УДК 631.316

В.А. Черноволов, А.Ю. Несмиян

ОЦЕНКА ВЛИЯНИЯ ОСНОВНЫХ ПАРАМЕТРОВ ПОЧВООБРАБАТЫВАЮЩИХ ОРУДИЙ НА ИХ СПОСОБНОСТЬ К КОПИРОВАНИЮ РЕЛЬЕФА ПОВЕРХНОСТИ ПОЛЯ

Ключевые слова: почвообрабатывающее орудие; копирование рельефа; поверхность поля; углы локальных склонов; продольная база орудия; общая длина орудия.

Введение. В сельскохозяйственном производстве широкое распространение получили операции поверхностной обработки почвы, для реализации которых зачастую применяют ору- дия с многорядным расположением рабочих органов [1]. При этом продольные размеры орудий, размещение опор, регулирующих глубину обработки почвы, могут существенно влиять на 
качество протекания технологического процесса [2].

Для современного сельхозмашиностроения характерна тенденция к увеличению линейных размеров почвообрабатывающих орудий, базирующаяся на следующих постулатах $[1,3,4]$ : пространственное «разнесение» опор способствует повышению устойчивости орудия в работе, снижению неравномерности глубины обработки почвы; приращение продольного расстояния между передними и задними опорами позволяет увеличить расстояние между рядами рабочих органов, снизить их взаимное влияние друг на друга (особенно при высоких скоростях работы), сократить вероятность забивания почвой и мортмассой (растительными остатками); увеличение высоты расположения рамы над поверхностью поля также сокращает вероятность забивания рабочих органов мортмассой; приращение длины прицепной сницы способствует стабилизации хода почвообрабатывающих орудий, снижению величины их угловых колебаний относительно точки прицепа. При этом очевидно, что увеличение размеров почвообрабатывающих орудий приводит к возрастанию их массы и себестоимости, снижению маневренно- сти, повышению эксплуатационных затрат и т. д. Тем не менее, ожидаемые преимущества предположительно позволяют компенсировать недостатки, благодаря чему общая направленность к росту продольных и вертикальных размеров почвообрабатывающих орудий сохраняется.

Задачей представленного исследования является аналитическая оценка влияния основных параметров почвообрабатывающих орудий на их способность копировать рельеф поверхности поля при работе.

Допущения и методы исследования. Исследование проводилось на примере анализа технологического процесса обработки почвы паровыми культиваторами, так как они являются одной из наиболее распространенных групп орудий для поверхностной обработки почвы, а к показателям их работы предъявляют более жесткие требования по равномерности глубины рыхления и «сплошности» обработки поверхности поля [2].

Рассмотрим траекторию движения прицепной серьги культиватора с жестко закрепленной прицепной сницей при копировании рельефа поверхности поля (рисунок 1).

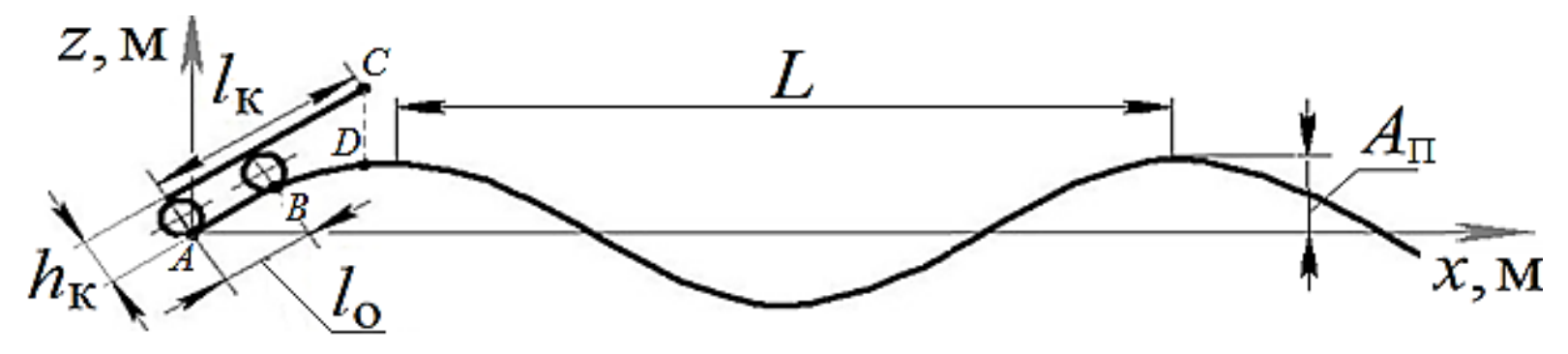

Рисунок 1

Схема перемещения культиватора по поверхности поля с учетом продольного рельефа:

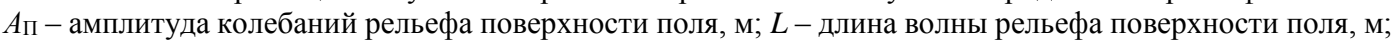
$l_{\text {к }}$ длина культиватора, м; $l_{0}$ - расстояние между передними и задними опорами (продольная база) куль-

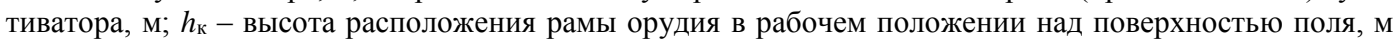

На рисунке 1 обозначены следующие характерные точки: $A$ - точка контакта задней опоры культиватора, например, катка с поверхностью почвы; $B$ - точка контакта передней опоры (передних опор) культиватора с почвой; $C$ - точка, соответствующая прицепной серьге культиватора; $D$ - точка проекции прицепной серьги культиватора на поверхность поля.

При проведении анализа были приняты следующие предположения: прицепная сница культиватора жестко связана с его рамой; прицепное устройство трактора находится в плавающем положении; копирование рельефа выполняется передними и задними копирующими колесами (или катками), при этом в случае применения катков они не смещаются относительно рамы орудия; в исходном положении точка контакта заднего колеса или катка орудия и почвы находится в начале координат; диаметры колес трактора и культиватора в работе остаются постоянными; под давлением колес культиватора и трактора почва не проседает или проседает, но на неизменную во времени величину.

Как правило, исследователи выделяют четыре характерных вида рельефа поверхности поля: макро-, мезо-, -микро- и нанорельеф [5-8]. Характеристики нано- и макрорельефов несопоставимы с линейными размерами почвообрабатывающих орудий, поэтому наибольшее влияние на глубину хода их рабочих органов будут оказывать мезо- и микрорельеф поверхности поля. В качестве основных характеристик рель- 
ефа поверхности поля, как правило, принимают средние длину волны $L$ и амплитуду $A_{\Pi}$ колебаний рельефа (рисунок 1) или средний угол $\alpha_{\mathrm{c}}$ локальных склонов, который также может быть

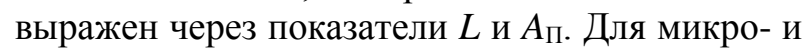
мезорельефа они варьируются в значительных диапазонах: средняя амплитуда колебаний рельефа поверхности поля $A_{\Pi} \approx 0,03-0,3 \mathrm{м}$, длина волны $L \approx 0,5-14,0$ м [5-8].

При проведении исследования будем задаваться значением координаты $x_{\mathrm{A}}$ точки А (рису-

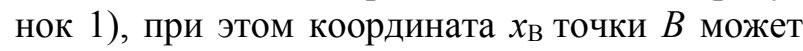
быть определена путем решения трансцендентного уравнения

$$
\left(x_{B}-x_{A}\right)^{2}+\left(\mathrm{z}_{B}-\mathrm{z}_{A}\right)^{2}=l_{\mathrm{o}}{ }^{2},
$$

где $\mathrm{z}_{A}$ и $\mathrm{z}_{B}-$ координаты точек $A$ и $B$ по вертикали, м.

$$
\begin{aligned}
& \mathrm{z}_{A}=A_{\Pi} \sin \left(\frac{2 \cdot \pi \cdot x_{A}}{L}\right), \\
& \mathrm{z}_{B}=A_{\Pi} \sin \left(\frac{2 \cdot \pi \cdot x_{B}}{L}\right) .
\end{aligned}
$$

Анализ уравнений (1), (2) и (3) позволил установить, что величина $\left(x_{B}-x_{A}\right)$ колеблется в диапазоне $(0,994 \ldots 1,0) l_{\mathrm{o}}$, т. е. с вероятностью более $99 \%$ можно принять $x_{B}=x_{A}+l_{\mathrm{o}}$.

Тогда координаты точки $C$

$$
\begin{aligned}
& x_{C}=x_{A}+l_{\mathrm{\kappa}} \cos \alpha-h_{\mathrm{\kappa}} \sin \alpha, \\
& \mathrm{z}_{C}=h_{\mathrm{\kappa}} \cos \alpha+z_{A}+l_{\mathrm{\kappa}} \sin \alpha .
\end{aligned}
$$

Координаты точки $D$

$$
\begin{gathered}
x_{D}=x_{C}, \\
\mathrm{z}_{D}=A_{\Pi} \sin \left(\frac{2 \cdot \pi \cdot x_{C}}{L}\right) .
\end{gathered}
$$

Ранее было оговорено, что при работе культиваторного агрегата навесное устройство трактора находится в плавающем положении, что позволяет компенсировать колебания, воспринимаемые ходовой частью трактора, и отклонения положения опор культиватора от плоскости положения опор трактора. При этом прицепное устройство трактора может перемещаться в диапазоне от $z_{\min }$ до $z_{\max }$ (например, для тракторов третьего тягового класса - от 230 до 660 мм) [9]. В то же время положение прицепной серьги культиватора зависит от положения опор культиватора и его длины и при определенном характере рельефа поверхности поля может выходить за зону возможного перемещения прицепного устройства трактора, что отрицательно скажется на показателях функционирования агрегата. При реализации реального процесса обработки почвы на участках, где точка прицепа культиватора выходит выше верхнего положения прицепа трактора, например, участок 3-4, происходит выглубление задних рабочих органов культиватора. На участках, где точка прицепа культиватора выходит ниже нижнего положения прицепа трактора (участок 1-2), происходит выглубление передних рабочих органов культиватора. Таким образом, для нормальной работы орудия необходимо, чтобы траектория движения прицепной серьги культиватора $\left(z_{C}=f(x)\right)$ не выходила за границы, очерченные траекториями движения прицепного устройства трактора при его предельных верхнем $\left(z_{\max }=f(x)\right)$ и нижнем $\left(\mathrm{Z}_{\min }=f(x)\right)$ положениях (рисунок 2). При построении графиков уровня поверхности поля координаты прицепа культиватора, верхнего и нижнего положений прицепного устройства трактора в рамках представленного исследования рассматривалась работа агрегата с трактором третьего тягового класса.

$z, \mathrm{M}$

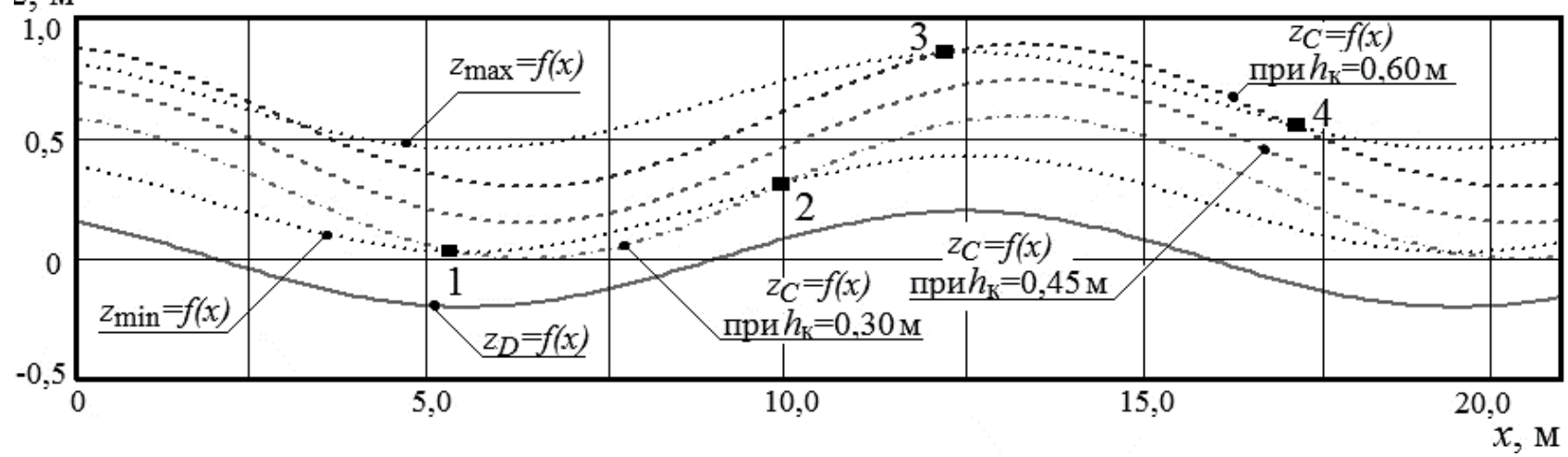

Рисунок 2

Траектории движения прицепных устройств культиватора и трактора при $A_{\Pi}=0,2 \mathrm{м} ; L=14$ м; $l_{\mathrm{o}}=3,5 \mathrm{м} ; l_{\mathrm{K}}=5 \mathrm{м}$

На основе анализа данных, представленных на рисунке 2, можно сделать вывод, что высота расположения рамы над поверхностью поля во время работы существенно влияет на способность орудия к копированию рельефа поверхности поля. Наиболее благоприятным является расположение рамы на высоте $h_{\mathrm{\kappa}}=0,5\left(z_{\max }+\right.$ $\mathrm{Z}_{\mathrm{min}}$ ). Как уменьшение, так и увеличение этого параметра приводит к возрастанию вероятности выхода траектории движения прицепного устройства орудия за оговоренные границы. При этом вероятность нарушения технологиче- 


\section{DOI: 10.31563/1684-7628-2017-43-3-77-83}

ского процесса может быть оценена количественно как отношение суммарной длины участков, на которых траектория прицепной серьги выходит за граничные условия, к средней длине волны рельефа поверхности поля [10].

$$
\mathrm{z}_{C}\left(x_{1}\right)=\mathrm{z}_{\min }\left(x_{1}\right), \mathrm{z}_{C}\left(x_{2}\right)=\mathrm{z}_{\min }\left(x_{2}\right), \mathrm{z}_{C}\left(x_{3}\right)=\mathrm{z}_{\max }\left(x_{3}\right), \mathrm{z}_{C}\left(x_{4}\right)=\mathrm{z}_{\max }\left(x_{4}\right),
$$

где $\mathrm{z}_{C}\left(x_{i}\right)$ - вертикальная координата прицепной серьги культиватора при соответствующем значении $x_{i} ; \mathrm{z}_{\min }\left(x_{i}\right), \mathrm{z}_{\max }\left(x_{i}\right)$ - вертикальные координаты тракторного прицепного устройства при его предельном нижнем или верхнем положении при соответствующем значении $x_{i}$.

Вероятность нарушения качества выполне-

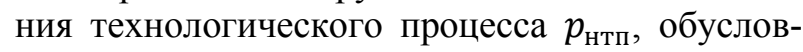
ленная несоответствием параметров культиватора рельефу поля,

$$
\begin{gathered}
p_{\text {нтп }}=0 \text { при } \delta \leq 0, \\
p_{\text {нтп }}=\frac{\Delta X_{24}+\Delta X_{57}}{L} \text { при } \delta>0 .
\end{gathered}
$$

Результаты исследований и их обсуждение. Графические зависимости, условно отражающие долю критических участков, на которых возможно нарушение качества технологического процесса, обусловленное несоответствием параметров культиватора рельефу поля, пред-
В общем виде

$$
\delta=\frac{x_{2}-x_{1}+x_{4}-x_{3}}{L}
$$

Горизонтальные координаты точек 1, 2, 3 и 4 могут быть найдены на основе анализа уравнений:

ставлены на рисунке 3 . Эти изолинии были получены расчетным путем для трактора третьего тягового класса при высоте расположения рамы над поверхностью поля $h_{\mathrm{\kappa}}=0,45$ м. Результаты графического анализа данных рисунка 3 позволяют сделать вывод, что увеличение углов локальных склонов на поверхности поля приводит к существенному увеличению вероятности нарушения качества процесса обработки почвы. Так, их увеличение менее чем на полтора градуса (с 3,3 до 4,5 град) приводит к возрастанию вероятности отрицательного исхода с 0 до $70 \%$ (при $l_{\kappa}<6$ м и $l_{\mathrm{o}}>3 \mathrm{~m}$ ). Снизить отрицательное влияние резко выраженного рельефа поля на качество обработки почвы можно путем уменьшения общей длины культиватора (за счет уменьшения продольного размера прицепной сницы) и увеличения расстояния между передними и задними опорами (продольной базы) орудия.

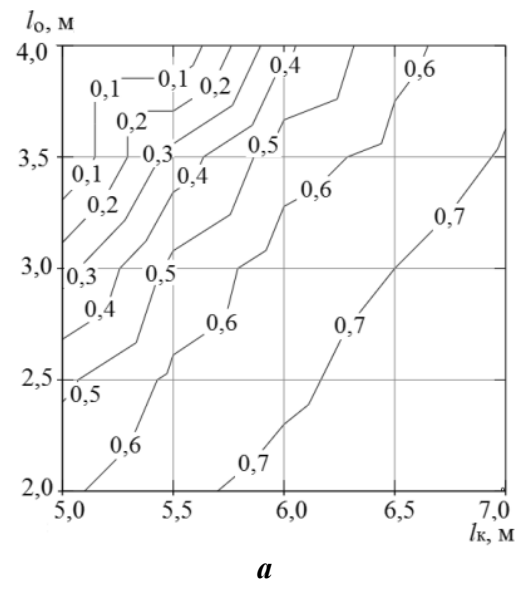

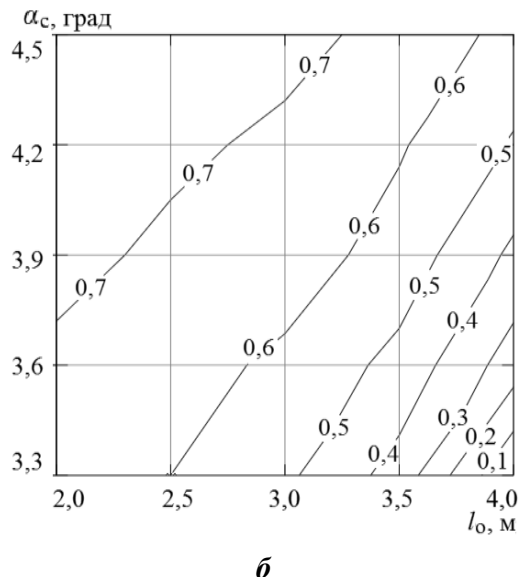

б

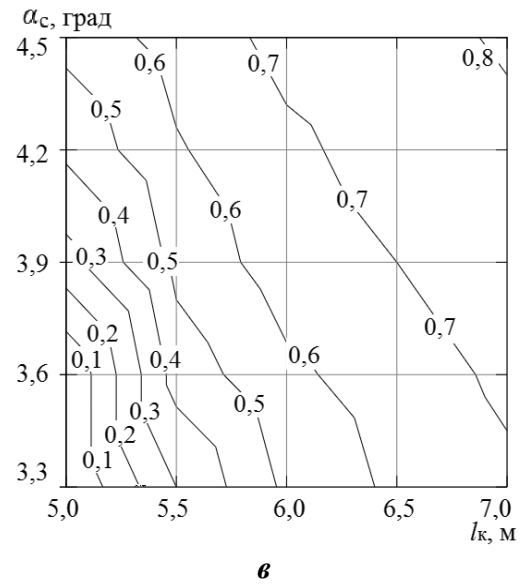

B

Рисунок 3

Изолинии вероятности нарушения качества технологического процесса, обусловленной несоответствием параметров культиватора рельефу поля: $\boldsymbol{a}$ - при среднем значении углов локальных склонов $\alpha_{\mathrm{c}}=3,9$ град; $\boldsymbol{\sigma}$ - при длине культиватора $l_{\mathrm{\kappa}}=6 \mathrm{м} ; \boldsymbol{\sigma}-$ при продольном расстоянии между крайними передними и задними опорами культиватора $l_{\mathrm{o}}=3 \mathrm{~m}$

Однако в то же время увеличение продоль-

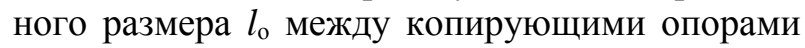
культиватора будет способствовать ухудшению копирования рельефа поверхности поля заключенными между ними рабочими органами. Причем чем дальше рабочий орган расположен от опоры, тем больше будет величина колебаний глубины обработки почвы, в связи с этим наибольших значений она будет достигать у рабочих органов, расположенных центрально между передними и задними опорами (рисунок
4). При анализе данных рисунка 4 было принято дополнительное предположение, что глубина обработки почвы несоизмеримо мала в сравнении со значениями длины культиватора и расстояния между его передними и задними опорами (меньше $5 \%$ ), поэтому в первом приближении с учетом незначительных угловых перемещений культиватора можно считать, что прямая, перпендикулярная поверхности почвы и проходящая через носок наральника «центрального» рабочего органа (т. Е), расположена при- 


\section{DOI: 10.31563/1684-7628-2017-43-3-77-83}

мерно вертикально. Тогда глубину обработки почвы можно определить как $a_{E}=\mathrm{z}_{E^{\prime}}-\mathrm{z}_{E}$ (где $E^{\prime}$ - точка на поверхности поля, расположенная вертикально над носком наральника (т. $E$ ) «центрального» рабочего органа).

Текущие координаты наральника «центрального» рабочего органа могут быть определены исходя из системы уравнений

$$
\begin{gathered}
x_{E}=0,5 x_{A}+0,5 x_{B}, \\
\mathrm{z}_{E}=0,5 \mathrm{z}_{A}+0,5 \mathrm{z}_{B}-a_{3} .
\end{gathered}
$$

Тогда вертикальная координата точки $E^{\prime}$

$$
\mathrm{z}_{E^{\prime}}=A_{\Pi} \sin \left(\frac{2 \cdot \pi \cdot x_{E}}{L}\right) .
$$

На рисунке 5 представлены траектории движения «центральных» рабочих органов культиватора при различных значениях продольной базы культиватора.
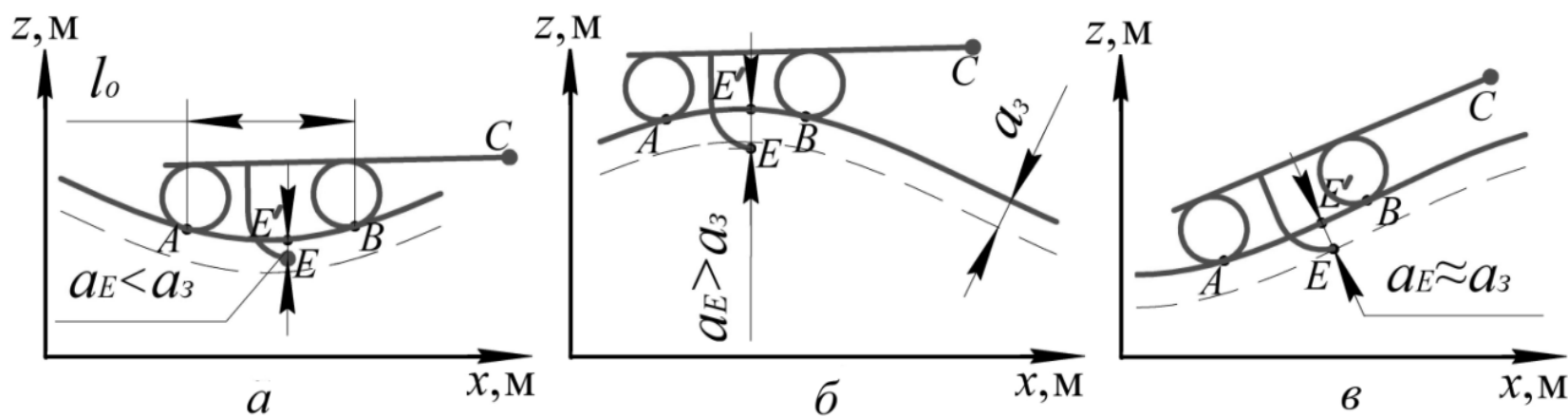

Рисунок 4

Схема влияния расстояния между опорами почвообрабатывающего орудия и рельефа поля на глубину обработки почвы «центральными» рабочими органами: $a$ - при глубине хода «центральных» рабочих органов $a_{E}$ меньше заданной $a_{3} ; \sigma$ - при глубине хода «центральных» рабочих органов $a_{E}$ больше заданной $a_{3} ; в$ - при глубине хода «центральных» рабочих органов $a_{E}$ равной заданной $a_{3}$

Анализ данных рисунка 5 позволяет заключить, что продольная база почвообрабатывающих орудий существенным образом сказывается на качестве реализуемого технологического процесса. В рассматриваемых диапазонах при увеличении параметра $l_{\mathrm{o}}$ с 2,5 до 3,5 м (на $1 \mathrm{~m}$ ) максимальное расчетное отклонение глубины обработки почвы от заданного возросло примерно на 0,03 м (на $20 \%$ ) и составило около 0,06 м (около $43 \%$ ), что существенно превышает допуск агротребований.

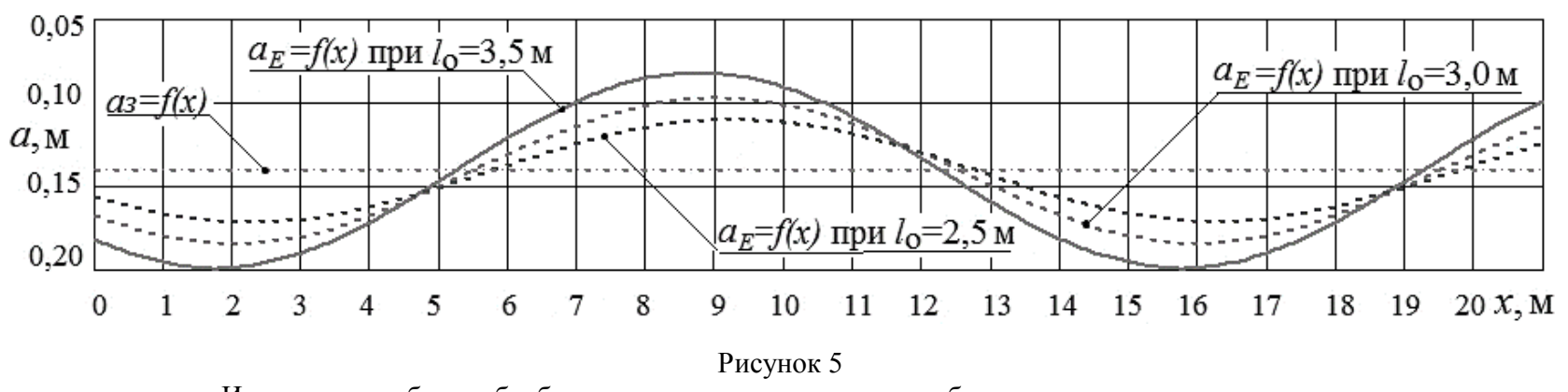

Изменение глубины обработки почвы «центральными» рабочими органами культиватора при различных значениях расстояния $l_{\mathrm{o}}$ между передними и задними опорами $\left(A_{\Pi}=0,2 \mathrm{м} ; L=14 \mathrm{м} ; a_{3}=0,14 \mathrm{м} ; h_{\mathrm{\kappa}}=0,45 \mathrm{м} ; l_{\mathrm{\kappa}}=5 \mathrm{м}\right)$

Выводы. Высота расположения рамы над поверхностью поля во время работы существенно влияет на способность орудия к копированию рельефа поверхности поля. Наиболее благоприятным является расположение рамы на высоте $h_{\mathrm{\kappa}}=0,5\left(z_{\max }+z_{\min }\right)$, где $z_{\max }$ и $z_{\min }-$ предельные возможные положение прицепного устройства трактора (верхнее и нижнее) над поверхностью поля. Увеличение углов локальных склонов на поверхности поля приводит к росту вероятности нарушения качества процесса обра- ботки почвы, что говорит о необходимости тщательного планирования полей. Снизить отрицательное влияние выраженного рельефа поля на качество обработки почвы можно путем уменьшения продольного размера прицепной сницы и увеличения расстояния между передними и задними опорами орудия. Однако в то же время увеличение продольной базы $l_{\mathrm{o}}$ почвообрабатывающих орудий приводит к повышению неравномерности глубины обработки почвы центрально расположенными рабочими органами, 


\section{DOI: 10.31563/1684-7628-2017-43-3-77-83}

поэтому компенсация мезонеровностей рельефа поля за счет увеличения продольного расстояния между опорами орудия нерациональна. В обоснованных пределах продольные размеры почвообрабатывающих орудий должны быть минимизированы. В целом проведенное моделирование показало, что при углах локальных склонов на поверхности поля до 3,6 град рациональными являются продольная база почвообрабатывающих орудий $l_{\mathrm{o}} \approx 3$ м, общая длина орудий $l_{\text {к }} \approx 5-6$ м. При увеличении углов локальных склонов, что характерно, например, для зон горного земледелия, длина прицепной сницы культиватора должна уменьшаться.

\section{Библиографический список}

1. Мазитов, Н.К. Техника - основа инновационной технологии обработки почвы [Текст] / Н.К. Мазитов, Я.П. Лобачевский, Л.З. Шарафиев и др. // Техника и оборудование для села. 2014. № 10 (208). С. 12.

2. Несмиян, А.Ю. Обоснование рациональной длины прицепной сницы широкозахватного культиватора [Текст] / А.Ю. Несмиян // Тракторы и сельхозмашины. 2016. № 6. С. 31-34.

3. ЗАО РТП «Зерноградское» [Электронный ресурс]. Режим доступа: rtp-zern.ru. Дата обращения: 03.02.2017 г.

4. Справочник конструктора сельскохозяйственных машин в двух томах [Текст] / Под ред. А.В. Красниченко. Москва: ВИСХОМ, 1961. $863 \mathrm{c}$.

5. Беспамятнова, Н.М. Научно-методические основы адаптации почвообрабатывающих и посевных машин [Текст] / Н.М. Беспамятнова. Ростов-на-Дону: Терра; Гефест, 2002. 176 с.

6. Ковриков, И.Т. Основы проектирования широкозахватных машин почвозащитного комплекса с учетом микрорельефа полей [Текст]: автореферат дисс. ... докт. тех. наук / И.Т. Ковриков. Новосибирск, 1982. 42 с.

7. Моделирование сельскохозяйственных агрегатов и их систем управления [Текст] / Под ред. А.Б. Лурье. Ленинград: Колос, 1979. $312 \mathrm{c}$.

8. Жаров, В.П. Научные основы оптимизации колебательных систем мобильных сельскохозяйственных машин по их показателям качества [Текст]: автореферат дисс. ... докт. тех. наук / В.П. Жаров. Ростов-на-Дону, 1980. 42 с.

9. ГОСТ 10677-2001 Устройство навесное заднее сельскохозяйственных тракторов 0,6-8. Типы, основные параметры и размеры. Межгосударственный стандарт [Текст]. Минск: Межгосударственный совет по стандартизации, метрологии и сертификации, 2001. 7 с.

10. Несмиян, А.Ю. Влияние продольных размеров парового культиватора на показатели копирования рельефа поля [Текст] / А.Ю. Несмиян // Вестник аграрной науки Дона. 2016. № 4 (36). C. 54-61.

\section{Сведения об авторах}

1. Черноволов Василий Александрович, доктор технических наук, профессор, профессор кафедры «Технологии и средства механизации агропромышленного комплекса» Азово-Черноморского инженерного института, ФГБОУ ВО Донской ГАУ, 347740, Россия, г. Зерноград Ростовской области, ул. Ленина, 21, e-mail: chernovolov.v@mail.ru.

2. Несмиян Андрей Юрьевич, канд. техн. наук, доцент, доцент кафедры «Технологии и средства механизации агропромышленного комплекса» Азово-Черноморского инженерного института, ФГБОУ ВО Донской ГАУ, 347740, Россия, г. Зерноград Ростовской области, ул. Ленина, 21, e-mail: nesmiyan. andrei@yandex.ru.

Задачей представленного исследования является аналитическая оценка влияния таких параметров почвообрабатывающих орудий, как продольная база, общая длина, высота расположения рамы, на равномерность глубины рыхления почвы. Исследование проводилось на примере анализа технологического процесса обработки почвы паровыми культиваторами, так как они являются одной из наиболее распространенных групп орудий для поверхностной обработки почвы, а к показателям их работы предъявляют более жесткие требования по равномерности глубины рыхления и «сплошности» обработки поверхности поля. Проведенное теоретическое исследование показало, что наиболее благоприятным является расположение рамы на высоте, равной половине возможного расположения по вертикали прицепного устройства трактора при его предельных верхнем и нижнем положениях. Увеличение углов локальных склонов на поверхности поля приводит к росту вероятности нарушения качества процесса обработки почвы, 
что говорит о необходимости тщательного планирования полей. Снизить отрицательное влияние выраженного рельефа поля на качество обработки почвы можно путем уменьшения продольного размера прицепной сницы и увеличения расстояния между передними и задними опорами орудия. Однако в то же время увеличение продольной базы почвообрабатывающих орудий приводит к повышению неравномерности глубины обработки почвы центральнорасположенными рабочими органами, поэтому компенсация мезонеровностей рельефа поля за счет увеличения продольного расстояния между опо- рами орудия нерациональна. В обоснованных пределах продольные размеры почвообрабатывающих орудий должны быть минимизированы. В целом проведенное моделирование показало, что при величине углов локальных склонов на поверхности поля до 3,6 град рациональными являются продольная база почвообрабатывающих орудий $l_{\mathrm{o}} \approx 3 \mathrm{м}$, общая длина орудий $l_{\mathrm{\kappa}} \approx 5-$ 6 м. При увеличении углов локальных склонов, что характерно, например, для зон горного земледелия, длина прицепной сницы культиватора должна уменьшаться.

V. Chernovolov, A. Nesmiyan

\title{
EVALUATING EFFECT \\ OF MAIN PARAMETERS OF TILLERS ON THEIR ABILITY TO FOLLOW FIELD SURFACE CONTOUR
}

\author{
Key words: tiller; contour following; field surface; angles of local slopes; a longitudinal base of the \\ tool; the total length of the tool; hitch frame.
}

\section{Authors' personal details}

1. Chernovolov Vasily, Doctor of technical sciences, professor of the «Technology and mechanization of agriculture» chair, Azov-Black sea engineering institute, Federal State Budgetary Educational Institution of Higher Education Don State Agrarian University, 347740, Russia, Rostov region, Zernograd, Lenin st., 21, e-mail: chernovolov.v@mail.ru.

2. Nesmiyan Andrey, Candidate of technical sciences, associate professor of the «Technology and mechanization of agriculture» chair, Azov-Black sea engineering institute, Federal State Budgetary Educational Institution of Higher Education Don State Agrarian University, 347740, Russia, Rostov region, Zernograd, Lenin st., 21, e-mail: nesmiyan.andrei@yandex.ru.

The aim of the present study is an analytical evaluation of the way such parameters of tillers as a longitudinal base, length, height of the frame have an effect on the uniform depth of soil ripping. The study was conducted on the example of analysis of technological process of treatment of the soil with general cultivators, as they were one of the most common groups of tools for surface tillage, and there were more rigid requirements to the indication of their work, such as the uniformity of the depth of loosening and the "continuity" of the field surface treatment. The study showed that the location of the frame at the height equal to half the possible location of the vertical hitch of a tractor at its maximum upper and lower positions was most favorable. Higher angles of the local slopes on the field surface leads to worse quality of the soil treatment process that suggests the need for careful planning of fields. Reducing negative impact of prominent field relief on soil quality can be achieved by reducing the longitudinal size of the hitch frame and increasing the distance between the front and rear legs of the tool. However, at the same time, the increase in longitudinal base of tillers increases the uniformity of depth of tillage with centrally located working bodies, therefore, the compensation of average irregularities of the field relief due to the increase in longitudinal distance between the tool supports is irrational. Reasonable longitudinal dimensions of the tilling equipment must be minimized. In general, the conducted simulation showed that when the value of the angles of the local slopes on the surface of the field was up to $3.6 \mathrm{deg}$, the longitudinal base of tillers at $l_{\mathrm{o}} \approx 3 \mathrm{~m}$, the total length of the tools $l_{\mathrm{K}} \approx 5-6$ is rational. The length of the hitch frame of the cultivator should be reduced when increasing the angles of the local slopes being common for example for areas of mountain agriculture.

(C) Черноволов В.А., Несмиян А.Ю. 